\title{
Article
}

\section{It's more than just travel CME: A case study of how an Emergency Medicine conference addresses educational needs of physicians}

\author{
Katie N Dainty PhD ${ }^{1,2}$, Rick Penciner MD ${ }^{1,3}$ \\ ${ }^{1}$ North York General Hospital; ${ }^{2}$ University of Toronto, Institute of Health Policy, Management and Evaluation; ${ }^{3}$ University of \\ Toronto Division of Emergency Medicine, Department of Family \& Community Medicine; Canada
}

\section{ABSTRACT}

Introduction: Travel-based continuing medical education (CME) has become a popular format for physicians looking to combine education with travel. Emergency Medicine Update Europe is a biennial accredited $\mathrm{CME}$ program combining high quality Emergency Medicine education with structured group activities including cycling, hiking and social activities. This unique design incorporates innovative educational practices but as a whole has not yet been evaluated.

Methods: This was a participant observation-based, ethnographic-style case study of the Emergency Medicine Update Europe conference in Provence, France in 2015. Participant interviews and embedded observation methods were used to collect data. Data was then analyzed using thematic content analysis techniques.

\section{INTRODUCTION}

The effect of traditional continuing medical education (CME) meetings (courses and workshops in various formats) on subsequent practice and patient outcomes has been called into question. There is some evidence that interactive workshops have resulted in moderately large improvements in professional practice, whereas
Results: We describe three phenomena from the data that we feel are highly influential in the success of the program and impact on learning. These include "social engagement and a sense of community"; "the value of a stimulating escape" and "the 'flat' faculty-learner relationships".

Discussion: These unique features, prioritized by participants, seem to be key to the apparent success of this model over more traditional CME approaches. To our knowledge this is the first empirical research in this area and improves our understanding of how to leverage these more sociologic components for more effective continuing medical education.

Keywords: continuing medical education, travel CME, ethnography, emergency medicine

didactic sessions have not ${ }^{1}$. Other reviews have demonstrated that educational meetings alone or combined with other interventions can improve professional practice. CME leads to improvement in physician performance and positive patient health outcomes if it is more interactive, uses more methods, involves multiple exposures, is longer, and is focused on outcomes that are considered important by physicians ${ }^{2}$. Tipping et

Correspondence: R. Penciner, North York General Hospital, 4001 Leslie Street, 630N, Toronto, ON M2K1E1, Canada; email: rick.penciner@utoronto.ca 
al also demonstrated that unstructured time at CME events helps physician learners integrate new material, solve individual practice problems and make new meaning out of their experience ${ }^{3}$. The interaction between colleagues is perceived as crucial in aiding the process of applying knowledge to practice.

All groups go through stages of development that impact on performance ${ }^{4}$. Outdoor, experiential, adventure-based education has been demonstrated to result in improvement in the rate of learning and has shown the greatest effect on; leadership, academics, independence, assertiveness, emotional stability, social comparison, time management, and flexibility ${ }^{5}$.

Travel-based continuing medical education (travel CME) or conference tourism has become a popular format for physicians looking to combine education with travel. A Google search brings forward more than 13 million hits of websites offering courses and programs around the world $^{6}$. However, the definition of such CME is not found in the literature and can be difficult to articulate. For the purposes of this paper, we are referring to educational offerings which combine continuing medical education and organized social activities in distant locations, usually for smaller groups of health care professionals. We are not referring to conferences or workshops which are simply held in desirable locations. Since most travel CME is for-profit non-academic programs, there is an absence of literature (both traditional and grey) describing these phenomena.

Emergency Medicine Update Europe is a biennial accredited CME program which combines high quality Emergency Medicine CME with organized group activities including; road cycling, hiking and social time. The course consists of approximately 15 hours of scheduled, formal interactive education (seminars, panel discussions and case-based learning) over 5 days facilitated by leading Emergency Medicine educators from North America. The participants are primarily Emergency Physicians from Canada, the United States and Australia. Previous courses have been conducted in France (2009), Italy (2011) and Spain (2013). The program is organized by North York General Hospital, a community academic hospital affiliated with the University of Toronto.

In order to contribute to the academic literature on novel types of continuing medical education we designed a study to capitalize on the opportunity to evaluate and understand what draws physicians to a CME program like Emergency Medicine Update Europe, the 'ethos' that is created during the program and how delivering education in this way might increase learning and uptake.

\section{METHODS}

\section{Study Design}

We undertook a participant observationbased ethnographic style study of the Emergency Medicine Update Europe program in Provence, France in 2015. Through the collection and integration of observations, interviews and documentary data, ethnographic research offers a qualitative approach with the potential to yield detailed and comprehensive accounts of different social phenomenon (actions, behaviour, interactions, beliefs) ${ }^{7}$. By using in situ observations, ethnographers can 'immerse' themselves in a social setting, thereby generating a rich understanding of social interaction.

Participant observation also provides researchers an opportunity to gather empirical insights into social practices which are normally immeasurable with other methods ${ }^{8}$. This is particularly innovative in education research as much of the qualitative work to date has focused on the collection of interviews (individual interviews, focus groups) to generate evidence. This has resulted in the creation of a largely perceptional account of what stakeholders think about medical education, rather than data of what actually happens during a program.

This study was approved by the Research Ethics Board at North York General Hospital prior to the conference (protocol code: 14-0053). 


\section{Study Setting:}

The Emergency Medicine Update Europe 2015 conference was held in Provence, France, October 4-10 2015. The event was attended by 82 participants (conference registrants and spouses/travel partners) from 3 countries (Canada, United States and Australia). There were 61 participants registered for the conference. This included physicians that practiced Emergency Medicine ( $\mathrm{n}=38)$, Emergency Medicine and Family Medicine $(n=11)$ and other medical disciplines $(n=12)$. The conference was organized by members of the North York General Hospital Emergency Services Program (located in Toronto, Canada) with expertise in continuing medical education and was designed based on a needs assessment (perceived and unperceived) utilizing innovative practices in medical education?.

\section{Data Collection:}

Primary data was collected in situ by an experienced qualitative researcher ("the researcher") during the entire six days of Emergency Medicine Update Europe program. The researcher is a $\mathrm{PhD}$-trained qualitative social scientist (KND) with 15 years experience as an investigator. She is not affiliated with the Emergency Medicine Update Europe program in any way and is not involved in the fields of emergency medicine or medical education. Data largely consisted of participatory field observations, interviews and interactions with the attendees. The researcher traveled daily with the program and participated in all activities with the group (both educational and social) taking detailed field notes about observations, stories, descriptions and interpretations.

The participant interviews took two forms; conversational interviews and more explicit oneon-one, semi-structured interviews. The conversational interviews were those discussions that the researchers had with the participants in a normal social scenario. In this case, data was collected via field notes including verbatim quotes where applicable. Explicit interviews were carried out when the researcher was able to sit down at a designated time with a participant to ask specific questions and explore emerging concepts. Each of these data collection methods was used strategically depending on the situation, and the researcher's discretion.

\section{Participant Sampling and Consent:}

Prior to the program, attendees were made aware of the evaluation and the nature of the researcher's involvement in the program and were given a copy of the letter of information. The researcher was formally introduced at the beginning of the program and it was announced that if anyone had any issue with the evaluation or methodology, they can speak to the program leadership and every effort would be made to exclude them from the data collection. This did not occur at any point during the conference. During casual conversation and more formal interviews, the researcher reminded the participant of their purpose at the program and consent was confirmed.

The group of attendees (including conference participants and travel partners) all participated in the observations and informal conversation, but 36 people were sampled for actual interviews. Qualitative sampling requires that enough data has to be generated to sufficiently explore the issues under investigation ${ }^{10}$. Data was collected throughout the seven day conference and both authors felt that thematic saturation was reached based on constant comparative analysis throughout the data collection. Additionally, the purpose of this sample was not to ensure representativeness but rather a convenience sample of participants with which to explore and understand, rather than measure, perceptions.

\section{Data Analysis:}

There are three aspects to qualitative data analysis: description, analysis and interpretation. Description refers to the recounting and describing of data, inevitably treating the data as fact. Analysis refers to the process of examining relationships, factors and linkages across the data 
points. Finally, the interpretation of data builds an understanding or explanation of the data beyond the data points and analysis. We used a thematic content analysis approach, emphasizing pinpointing, examining, and recording patterns (or "themes") within data. Handwritten field notes were transcribed verbatim into the database for analysis. The analytic process followed guidance by Braun and Clarke ${ }^{11}$. The researcher independently analyzed data inductively and developed a coding structure to apply to the full data set. After coding all data, patterns were identified across codes to create higher-level, explanatory categories or themes, and examine nuances within the emerging themes. Data analysis also involved triangulating observational and interview findings and discussion of emerging themes with the second author ${ }^{12}$. This provided an opportunity to confirm historical details and expectations of the program but did not influence the researcher's interpretations of the data.

\section{RESULTS}

\section{The EMU Europe Context}

Based on extensive observational field notes we begin with a description of the EMU Europe conference in order provide context for the qualitative results to follow.

There seemed to be a sense of comradery from the minute we boarded the bus from the train station to the hotel. It was a long ride, quiet ride but there was a sense of anticipation and many were rekindling friendships from past trips. The bus pulled up at the hotel which would be our home for the next 7 days and as we unloaded, the conversation was vibrant among all of the participants. Many knew what to expect as they had been on several EMU Europe conferences before and some were first-timers, excited but anxious to get settled and started.

Each day was structured similarly; conference participants were up for breakfast and lectures at $7 \mathrm{am}$ and spent until noon in a tight schedule of clinical presentations. The presenters were hand-picked not only for their clinical acumen but their demonstrated ability to present in unique ways and really capture the audience. There was always discussion and story-telling to enhance the technicalities. Despite the physical exhaustion from the intense cycling and many attendees having spouses or partners along on the trip, no one missed the morning education sessions; there were no empty seats. Over lunch the conversations continued and expanded to include discussions between faculty and attendees about the morning content as well as more philosophical topics such as career choices and work-life balance.

The afternoons were reserved for exercise in the form of road cycling and hiking. Participants joined their spouses and prepared for what turned out to be very vigorous physical activity. A professional cycling company had mapped out the best routes for our $50+\mathrm{km}$ daily cycling rides and expert guides manoeuvred the hikers through forests and over mountains to nearby villages and historical locales. Most nights we were free to sample the local food and drink on our own in the nearby village. Dinner groups formed during the afternoon and varied through the week, however the conversation at the tables almost always came back to emergency medicine, career and "stories from the trenches" (their language).

Within this rich context, the data collected revealed three phenomena that we feel are what have been highly influential in the success of the program and impact on learning. The first is "social engagement and a sense of community". Involvement in group physical and social activities supports more interactive learning and people affiliate with this as a group that they enjoy and feel good learning with. The second is "a stimulating escape". This is the opportunity for high quality education and stimulating travel to be provided in an efficient package. The third is "the 'flat' faculty-learner relationships". This is created through accessibility and innovative teaching and is a key component of the quality of the education. 


\section{Social Engagement \& Sense of Community}

The agenda of the trip is designed in such a way that the participants are engaged in either a learning or a social activity as a group most of the day. This design feature seemed to be particularly influential in creating a sense of community and a collegial learning space where attendees felt comfortable to ask questions or bring alternative perspectives to the clinical conversations.

The trip is organized around road cycling in world-class venues as the main social activity. This obviously draws a certain type of participant to the program, and the influence of physical activity or fitness was not insignificant. Participants felt that the combination of intensive medical education with intensive physical activity was a very effective balance and made the learning environment much more fertile.

"I think there might be something to the idea of the exercise increasing the blood flow to our brains so we can really soak in the information that's presented." [Participating Physician]

Many participants also commented that they felt what made the program attractive was the group of people that attend. There were several repeat attendees, many of whom had attended all four iterations of the program.

"It's the people - I like learning and socializing with this group of people" [Participating Physician]

"It has the same feeling as summer camp....it's summer camp for ER docs and you get that same feeling of coming back, seeing your pals year after year and learning useful things." [Participating Physician]

\section{A Stimulating Escape}

It was common for participants to talk about how this trip fulfills two important life components for them: travel and education, in a very efficient way. The importance of the "efficiencies" of combining them was quite evident and the nature of the fully facilitated educational and social program was very enticing to the physicians.

"I value both but I don't always have the time to do both, so this is the perfect situation for meespecially since I can also bring my wife. I don't have to choose or prioritize, it's all included." [Participating Physician]

"I'm usually the one who researches our trips and plans everything out so it's very nice to be able to come here and know that everything is taken care of; I can concentrate on learning and enjoying the social stuff because I don't have to worry about what's going to happen next." [Participating Physician]

\section{"Flat" Faculty-Learner Relationships}

Almost unanimously the attendees talked about the influence of the faculty in their learning and enjoyment of the program. Several people used the term "accessible" to not only refer to their physical accessibility due to travelling together but also as an important feature of their approach to teaching.

"...the fact that I can follow-up with [Dr. X] over a glass of wine at lunch following his lecture is invaluable" [Participating Physician]

"All of the faculty are just very unassuming, very approachable and have been there [referring to them all being practicing ED physicians] so they are very easy to talk to and ask questions of..." [Participating Physician]

The participant's experience of the faculty is in many ways a function of considerations made long before the trip begins as there is a very purposeful selection process for teachers.

"We select faculty based on who we would like to hang out with for a week... who we would like to have a beer with and of course who we know are 
really innovative, knowledgeable speakers" [Trip Organizing Committee member]

Finally, many of the faculty also remarked that they enjoy teaching in this program because it is a very comfortable group of "thirsty learners" despite so many of them having several years' experience in the field of Emergency Medicine.

"It's about using different ways to exchange knowledge; I do far more teaching on the hikes or at dinner than in the lecture." [Senior Faculty Member]

"It's really important to keep it real for these guys, they aren't trainees, they are long time docs (for the most part) and so you need to teach them in a way that resonates with their practice" [Physician Participant; Department Chief]

\section{DISCUSSION}

Our case study of the Emergency Update Europe program illuminated three critical features which appear to underpin a successful formula for this type of program; we have labelled these in no particular order as a) creating a sense of community, b) efficiency in combining learning and travel and c) unique faculty-learner relationships. While travel-based CME is not new and in some ways these findings may not be surprising, they are novel in the sense that to our knowledge this is the first formal study of what makes this type of educational program repeatedly attractive to participants and a potentially more successful form of knowledge dissemination.

Over the years, it has been shown that continuing medical education (CME) plays a critical role in improving patient outcomes, reducing healthcare costs, and enhancing the overall quality and efficiency of the healthcare system - both in terms of educated and proficient physicians and through serving as a conduit for medical progress and innovation ${ }^{13}$. High competition for time and resources has forced CME providers to be innovative themselves in providing unique opportunities for physicians to access the necessary education to be current and effective.

The concept of creating a "sense of community" has been developed in community psychology to characterize the relationship between individuals and social structures, with four proposed elements: membership (ie, the feelings of belonging), influence (ie, a sense of mattering), needs fulfillment (ie, feelings about the member's needs are met in the community), and emotional connection (ie, the beliefs or commitment that members share history, common places, time together, and similar experiences) ${ }^{14}$. The reference to summer camp in the exemplar quote, while said somewhat in jest, is quite useful in drawing connection to the social impact of this type of program. Much of what we found to be of importance to participants is indeed intangible forms of social capital that they may not find in other medical educational offerings and which in turn enrich the learning experience in a particularly valuable way. A recently published commentary by Zieglstein highlights that in the case of medical trainees, the "potential for social connection and engagement as well as group identification can promote well-being and avoid burn-out" $" 15$. He suggests that creating structured opportunities for trainees to establish meaningful connections with others in the learning environments is the way of the future. Based on our findings we would argue that this is true throughout the life course and not just for trainees. Although all continuing medical education cannot be as group intensive as this particular design, it does draw attention why siloed, didactic knowledge transfer is likely not effective for this type of physician.

Finally, the education literature tells us that when teachers form positive bonds with learners, classrooms become supportive spaces in which students can engage in academically and socially productive ways ${ }^{16}$. This notion seems to hold true in the setting we studied; the accessibility and approach of the selected faculty members was a key piece of what made the educational program successful in the eyes of the participants 


\section{Strengths and Limitations of the Work}

While most CME programs evaluate satisfaction of the participants, very few take the next step to truly understand how learning occurs and what brings participants to particular programs. By employing an ethnographically informed case study approach, we feel this study makes a significant academic contribution to the field of medical education research and provides insightful feedback to inform future CME program design. As with all research, this study has some inherent limitations. The findings are based on observation and interaction during a single CME event with a small sample of participants. However, given the high rate of return participants we feel that observing this version of the program allows us to make representative conclusions about the Emergency Medicine Update Europe program as a whole. Secondly, we did not collect follow-up information about the actual effectiveness of knowledge translation during the program. This would require more in-depth longitudinal quantitative follow-up and was not aligned with the objective of this evaluation.

\section{CONCLUSION}

While each travel CME will be unique, there appears to be some common elements that lead to success - building a sense of community, providing a stimulating escape and choosing faculty with specific teaching styles - that contribute to the educational success of this model. To our knowledge this is the first empirical research in this area and improves our understanding of how to leverage this approach for more effective continuing medical education.

\section{Declaration of Interests}

Rick Penciner is the Course Director of the Emergency Medicine Update Europe conference (unpaid). Katie Dailty's travel costs to attend the 2015 conference were paid for by a grant from the North York General Hospital Emergency Services Program. Neither author receives any ongoing financial compensation related to the Emergency Medicine Update Europe conference.

\section{About the Authors}

KATIE DAINTY is a PhD trained qualitative social scientist and Research Chair at North York General Hospital. She is an Assistant Professor in the Institute of Health Policy, Management and Evaluation, University of Toronto.

RICK PENCINER is the Director of Medical Education and a practicing Emergency Medicine physician at North York General Hospital and Course Director of Emergency Medicine Update Europe. He is an Associate Professor in the Division of Emergency Medicine, Department of Family \& Community Medicine, University of Toronto.

\section{Acknowledgements}

The authors would like to acknowledge all of the participants in the Emergency Medicine Update Europe trip in 2015 for so graciously accepting the researcher's presence and being willing to give of their time for interviews and discussions 


\section{REFERENCES}

1. Davis D, Galbraith R. 2009. American College of Chest Physicians Health and Science Policy Committee. Continuing medical education effect on practice performance: effectiveness of continuing medical education: American College of Chest Physicians Evidence-Based Educational Guidelines. Chest. Mar;135(3 Suppl):42S-48S.

2. Cervero RM and Gaines JK. Effectiveness of Continuing Medical Education: Updated Syntheses of Systematic Reviews. Accreditation Council for Continuing Medical Education; July 2014. Available at:

http://www.accme.org/sites/default/files/2014_Effectiveness_of_Continuin g_Medical_Education_Cervero_and_Gaines_0.pdf Last accessed on January 31, 2018

3. Tipping J, Donahue J, Hannah E. 2001. Value of unstructured time (breaks) during formal continuing medical education events. J Contin Educ Health Prof. Spring;21(2):90-6.

4. Tuckman, BW; Jensen MAC. 2010. Stages of Small-Group Development Revisited in Group Facilitation; St. Paul 10:43-48

5. Hattie J, Marsh HW, Neill JT, Richards GE. 1997. Adventure Education and Outward Bound: Out-of-Class Experiences That Make a Lasting Difference. Rev of Educ Research. 6(1): 43-87

6. Google search - last accessed September 19 2018

https://www.google.ca/search?q=travel+cme $\& \mathrm{rlz}=1 \mathrm{C} 1 \mathrm{QJDB}$ enCA776CA776\&oq $=$ trav el+CME\&aqs=chrome.0.016.3151j0j8\&sour ceid $=$ chrome \&ie $=$ UTF- 8

7. Reeves S, Kuper A, Hodges BD. 2008. Qualitative research methodologies: ethnography. British Medical Journal. Aug 7; 337:a1020.
8. Kawulich BB. 2005. Participant Observation as a Data Collection Method. Forum: Qualitative Social Research. 6(2), Art. 43

9. Penciner R. 2015. Crowdsourcing: an instructional method at an emergency medicine continuing education course. Canadian Journal of Emergency Medicine. Jul;17(4):433-6.

10. Guest G, Bunce A, Johnson L. 2006. How Many Interviews Are Enough? An Experiment with Data Saturation and Variability. Field Methods. 18(1): 59-82

11. Braun V, Clarke V. Using thematic analysis in psychology. Qualitative Research in Psychology. 2006;3(2):77-101.

12. Bernard HR \& Ryan GW. 2010. Analyzing Qualitative Data: Systematic Approaches. Sage Publications, Thousand Oaks (CA). 2010.

13. Bloom BS. 2005. Effects of continuing medical education on improving physician clinical care and patient health: a review of systematic reviews. International J Technol Assess Health Care. Summer; 21(3):380-5.

14. Chavis DM, Hogge JH, McMillan DW, Wandersman A. 1986. Sense of community through Brunswick's lens: A first look. Journal of Community Psychology. 14(1), 24-40.

15. Ziegelstein RC. 2017. Creating Structured Opportunities for Social Engagement to Promote Well-Being and Reduce Burnout in Medical Students and Residents. Academic Medicine. Epub ahead of print Dec 262017. DOI: 10.1097/ACM.0000000000002117

16. Hamre BK \& Pianta RC. 2001. Early Teacher-Child Relationships and the Trajectory of Children's School Outcomes through Eighth Grade. Child Development. 72(2): 625-638. 